\title{
An analysis of the dynamics of changes to water levels in the open piezometers of the Pieczyska dam in the study period between January 2016 and April 2017
}

\author{
Stanisław Lach $^{1, *}$ \\ ${ }^{1}$ AGH University of Science and Technology, Faculty of Mining Surveying and Environmental \\ Engineering, Department of Environmental Management and Protection, 30 Mickiewicza Av., 30-059 \\ Krakow, Poland.
}

\begin{abstract}
The construction This paper aims to analyze the changes in trends of water levels in open piezometers installed at the dam in Pieczyska, which is the only seepage dam in Poland constructed via the silting technique. The scope of the research includes the analysis of piezometric data for each of the 82 active piezometers installed on the dam from January 2016 to April 2017 and taking into consideration the accident which occurred in February 2016, during which at the downstream of the dam there was hydraulic piping, following which ca. $150 \mathrm{~m}^{3}$ of soil was eroded. A Statistical Rosner's test for identifying and rejecting outliers was performed before carrying out the analysis of the piezometric data. A hypothesis was formulated that change in the trend occurred after the accident in February 2016. Using the method of least squares, for each open piezometer, two trend lines were matched to its water levels - the first one for the period January 2016-February 2016 and the second one for the period March 2016-April 2017. In this way, two slope coefficients for the linear function were obtained, together with the estimation of their errors. These slopes were compared using a statistical parallelism test.
\end{abstract}

\section{Introduction}

In order to ensure the safety and reliability of impounding structures, continuous monitoring is carried out, aimed at assessing and predicting changes that may occur in its structure or foundation [1]. Thanks to special warning and alarm systems, it is possible to control hydraulic structures, which later also helps to effectively prevent potential failures or disasters. These systems are based on the results of observations and control surveys of basic quantities characterizing the state of the structure itself and its surroundings [2]. The most common ones are piezometric measurements, which allow for measuring water levels in the open standpipe piezometer or measuring water pressure in the closed standpipe piezometer [3]. Measurements of water levels in piezometers make it possible to control the phenomenon of seepage through the structure, and also help in detecting changes occurring

\footnotetext{
*Corresponding author: slach@agh.edu.pl
} 
in the dam. Intensive seepage processes may cause changes in the soil structure and contribute to the loss of the structural stability of the dam. As far as the safety of hydraulic structures is concerned, the most favorable situation occurs when water levels in piezometers oscillate around a constant value. This phenomenon proves stable seepage processes in the core and in the foundation of the dam. The increasing (or decreasing) trend may indicate the movement of small particles in the core or in the foundation (suffosis), which may eventually lead to the local exceedance of the of permissible seepage gradients, and thus lead to a situation posing a threat to the safety of the dam [4]. According to ICOLD, in $15 \%$ of all cases, suffosis is the primary cause of disasters in earth-filled and rock-filled dams, while in $13 \%$ of cases, this process is an additional cause [5]. Although the phenomenon of moderate intensity seepage cannot be considered undesirable, the one which is particularly intense may cause changes in the soil structure and result in the facility losing its stability. It is particularly important to pay attention to the almost imperceptible symptoms that may precede the occurrence of a failure or a disaster of a hydraulic structure. An example is the hydroelectric power plant in Dychów, where in 1997 the failure of the drainage system caused the groundwater level to rise in the silty formations of the natural slope, and the liquefied plastic mass flowed into the power plant building causing flooding of the turbine generator sets and excluding the plant from operation for 8 months [6].

\section{Material and methods}

The analyzed earth-fill dam is classified in the 1st class of the importance of hydraulic structures. It is located in Pieczyska, on the Brda River at $49+115 \mathrm{~km}$ from its source, and impounds water to the ordinate of $81.50 \mathrm{~m}$ above the mean sea level or, in emergency cases, to the elevation of $82.00 \mathrm{~m}$ above the mean sea level. The dam is equipped with a bottom outlet used to transport water from the upper to the lower reservoir, as well as to periodically rinse the old riverbed of the Brda River in Koronowo [7]. The dam is not equipped with a spillway and therefore, in the case of reservoir overfilling, the water will overflow through the land depression in the area of the eastern end of Białe Lake. The earth-filled dam in Pieczyska closes the catchment area of $4109 \mathrm{~km}^{2}$. The height of the dam is $23.5 \mathrm{~m}$, and its length is $340 \mathrm{~m}$. The slope of the upstream face in the upper part is $1: 3$, and in the lower part 1:4. The slope of the downstream face is $1: 4$ in the upper part and 1:5 in the lower part. The upstream face of the dam core, at the section between the ordinates 84.50 and $75.00 \mathrm{~m}$ above the mean sea level, was secured with concrete slabs, and the downstream slope - by turfing. The subsoil of the dam is stratified. It is built of medium sand (MSa), fine sand (FSa) and sandy gravel (grSa), and locally of poorly permeable silty sand (grsiSa, grclSa). The core of the dam in Pieczyska was made of fine-grained and middle-grained sand using the deposition method [1]. At the length of $130 \mathrm{~m}$ below the basin, the bottom and slopes of the Brda riverbed are reinforced with concrete slabs with drainage holes filled with aggregate. The task of the drainage system is to capture the water seeping through the dam in such a way as to prevent harmful and dangerous structural changes to the soil, as well as to maintain the curve of depression below the depth of ground freezing level.

From the very beginning of the dam's operation, there have always been problems with suffosis. There were numerous seepage failures in the outlet channel, together with the upheaval of the ground. For this reason, in 1976-1981 the dam was rebuilt. The bottom outlet and the dam were lengthened by addition of its lower part with a slope of 1:10. Thanks to the conducted modernization, the dam was able to remain in service, although the occasional upheaval of fine soil particles occurred in the outlet channel, i.e. outside the structure's core. In February 2016, at the lower part of the dam, in the bottom of the outlet 
channel, there was a hydraulic failure together with the upheaval of about $150 \mathrm{~m}^{3}$ of soil. There was an outflow of the water-soil mixture from one of the drainage holes in the bottom plate on the right side of the outlet channel, at a distance of about $10 \mathrm{~m}$ from the drainage ditch. At the same time, in the lower part of the right slope of the dam, a depression of land was observed, with a maximum depth of about $0.5 \mathrm{~m}$. The seepage output measured at the end of the outlet channel did not change, which proved that the failure was of a local character and did not derive directly from the upper water level. Two weeks before the failure, within about three days, the water table dropped by about $1.00 \mathrm{~m}$ in piezometers $\mathrm{P} 140 \mathrm{~B}$ and $\mathrm{P} 140 \mathrm{C}$ located in the area of the later subsidence, and in piezometers P126, P132, P131, and P146 located within a dozen to several dozen meters from the sinkhole. The piezometers located further reacted with smaller changes (Fig. 1) [8].

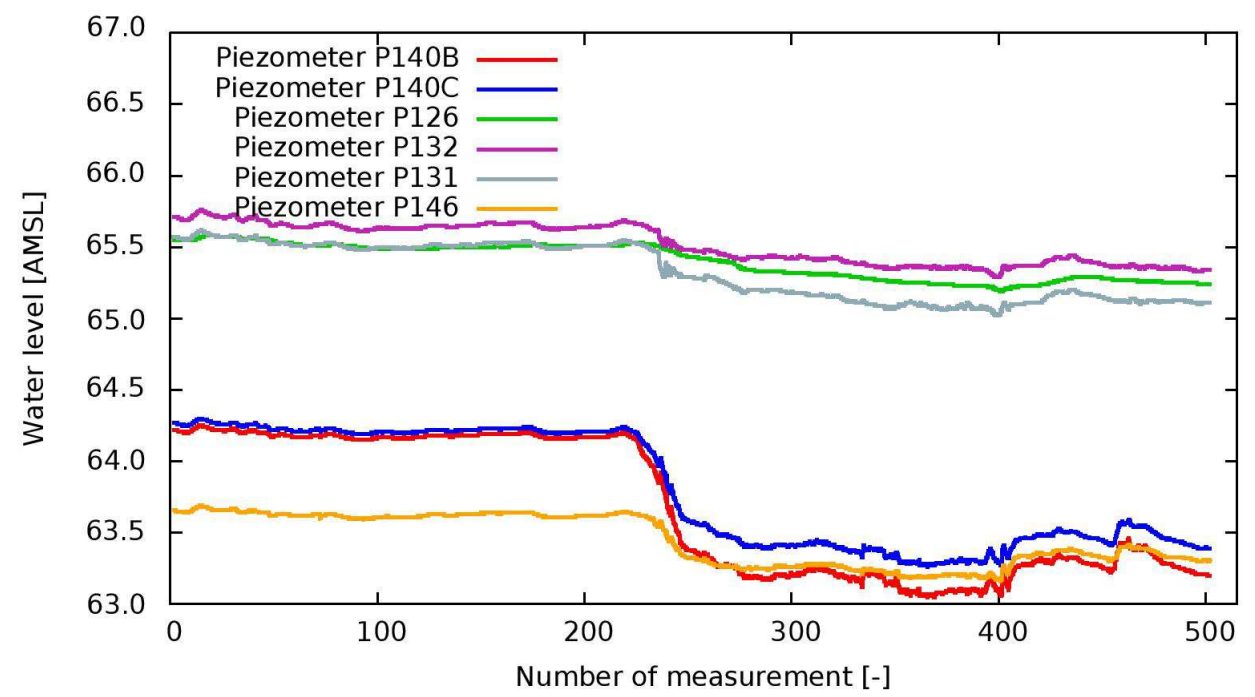

Fig. 1. Water level decrease in piezometers P140B, P140C, P126, P132, P131, and P146 two weeks before the occurrence of hydraulic failure.

The aim of the article was to analyze the dynamics of changes in water levels in open standpipe piezometers of the dam in Pieczyska in the period from January 2016 to April 2017. The subject of the analysis were changes in the level of the water table, observed in 82 open standpipe piezometers of the dam in Pieczyska, taking into account the previously mentioned failure that occurred in February 2016. Fig. 2 demonstrates the distribution of the piezometers at measurement sections of the earth-filled dam in Pieczyska. 


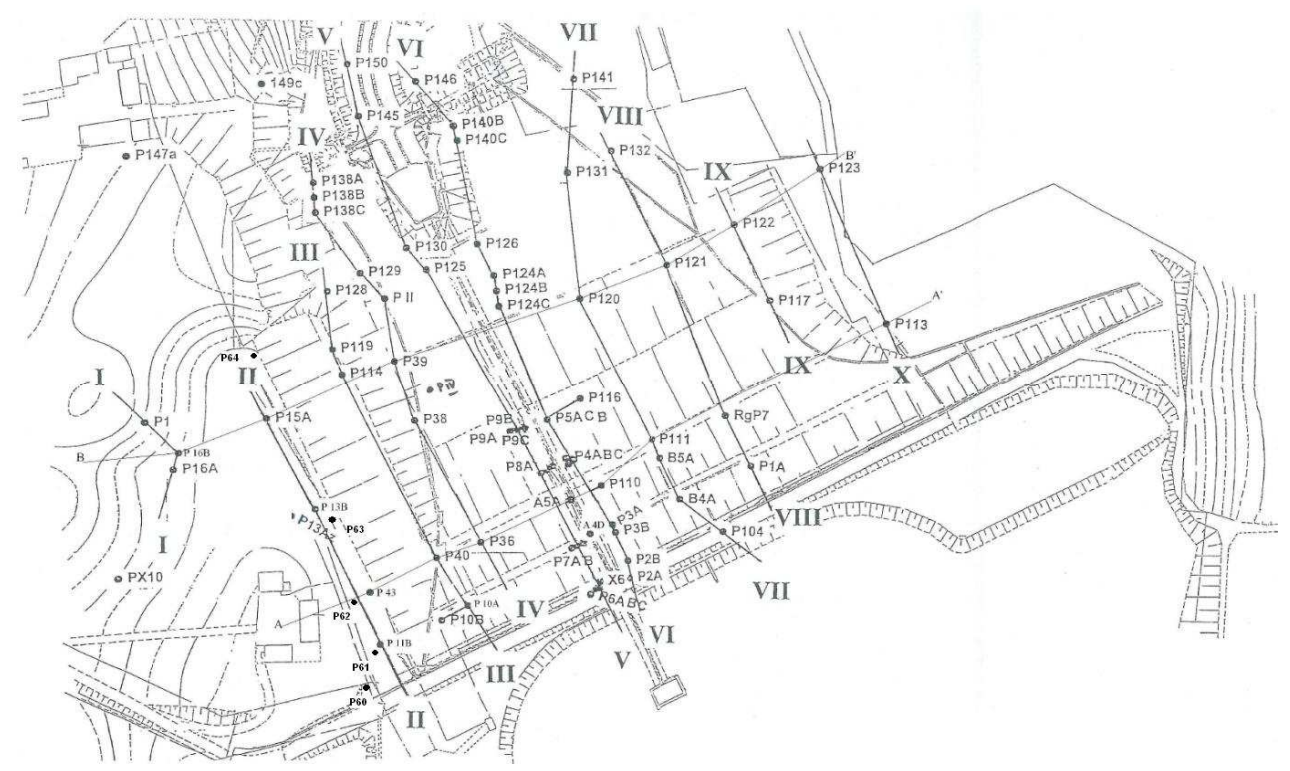

Fig. 2. Distribution of piezometers at measurement sections of the Pieczyska dam [7].

For each piezometer, 90758 piezometric measurements were performed, which were made available by the Koronowo Hydroelectric Power Station. Before the analysis of the piezometric data, Rosner's statistical test was used, thanks to which it was possible to detect and remove outliers [9]. As a result, a total of 12122 observations were removed from the data set, which accounted for a total of $0.16 \%$ of all results.

Using an open source software package, for example Gretl, the methodology of the analysis involved creating graphs of changes in the water levels in open piezometers, and then calculating trend lines for each piezometer using the least squares method. The least squares method allowed finding a straight line that would be best "adjusted" to the measurement points collected in the graph. Parameters of the straight line were selected so that the sum of the squares of differences between experimental values $y_{i}$ and calculated ones $a_{i} x+b_{i}$ was as small as possible. In this way, the values of the slope coefficient $a$ and the intercept $b$ were obtained.

Graphs for 82 open piezometers of the dam in Pieczyska were drawn, which illustrated the variability of the water levels in the study period between January 2016 and April 2017 and adjusted trend lines with a variable coefficient $a$, taking into account the period from January 2016 to February 2016 and from March 2016 to April 2017. For each piezometer, $\hat{y}_{1}=a_{1} x+b_{1}$ and $\hat{y}_{2}=a_{2} x+b_{2}$ were obtained, respectively. Then, using Gretl software, linear regression functions (trend lines) with different coefficients $a$ were compared for each piezometer from January 2016 to February 2016 and from March 2016 to April 2017. A test of significance for the hypothesis of equality of two linear regression coefficients, called the parallelism test, was used for this purpose [3]. The hypothesis $H_{0}: a_{l}=a_{2}$ was formulated against the alternative hypothesis $H_{l}: a_{1} \neq a_{2}$,. Then, for both trials, the sum of the squares of deviations of regression from these straight lines was calculated according to the Formula:

$$
\sum_{i=1}^{n_{1}}\left(y_{i 1}-\hat{y}_{i 1}\right)^{2} \text { and } \sum_{i=1}^{n_{2}}\left(y_{i 2}-\hat{y}_{i 2}\right)^{2}
$$


The value of statistic was calculated according to the Formula:

$$
t=\frac{a_{1}-a_{2}}{S_{a_{1}-a_{2}}}
$$

where:

$$
S_{a_{1}-a_{2}}=\sqrt{\frac{\sum_{i=1}^{n_{1}}\left(y_{i 1}-\hat{y}_{i 1}\right)^{2}+\sum_{i=1}^{n_{2}}\left(y_{i 2}-\hat{y}_{i 2}\right)^{2}}{n_{1}+n_{2}-4}\left(\frac{1}{\sum_{i=1}^{n_{1}}\left(x_{i 1}-\bar{x}_{1}\right)^{2}}+\frac{1}{\sum_{i=1}^{n_{2}}\left(x_{i 2}-\bar{x}_{2}\right)^{2}}\right)}
$$

Assuming that the verified hypothesis $H_{0}$ is true, the above-mentioned statistic is characterized by t-distribution with $\left(\mathrm{n}_{1}+\mathrm{n}_{2}-4\right)$ degrees of freedom. From the table of this distribution for a predetermined significance level of $\gamma=0.05$ and for $\left(n_{1}+n_{2}-4\right)$ degrees of freedom, such critical value $t_{\gamma}$ was read so that $\mathrm{P}\left\{|\mathrm{t}| \geq \mathrm{t}_{\gamma}\right\}=\gamma$. Comparing the calculated value of $t$ statistic with the critical value $\mathrm{t}_{\gamma}$, the following inequality was obtained: $|\mathrm{t}| \geq \mathrm{t}_{\gamma}$ or $|\mathrm{t}|<\mathrm{t}_{\gamma}$. In the first case, the hypothesis $H_{0}$ was rejected, and in the second case there were no grounds for rejecting the hypothesis $H_{0}$ [9].

\section{Study results}

Table 1 demonstrates the results obtained for the open standpipe piezometers of the dam in Pieczyska. Fig. 3 illustrates an example of a time series for the P15A piezometer for which the $H_{0}$ hypothesis was rejected.

Table 1. Results obtained for open piezometers at the dam in Pieczyska from January 2016 to April 2017.

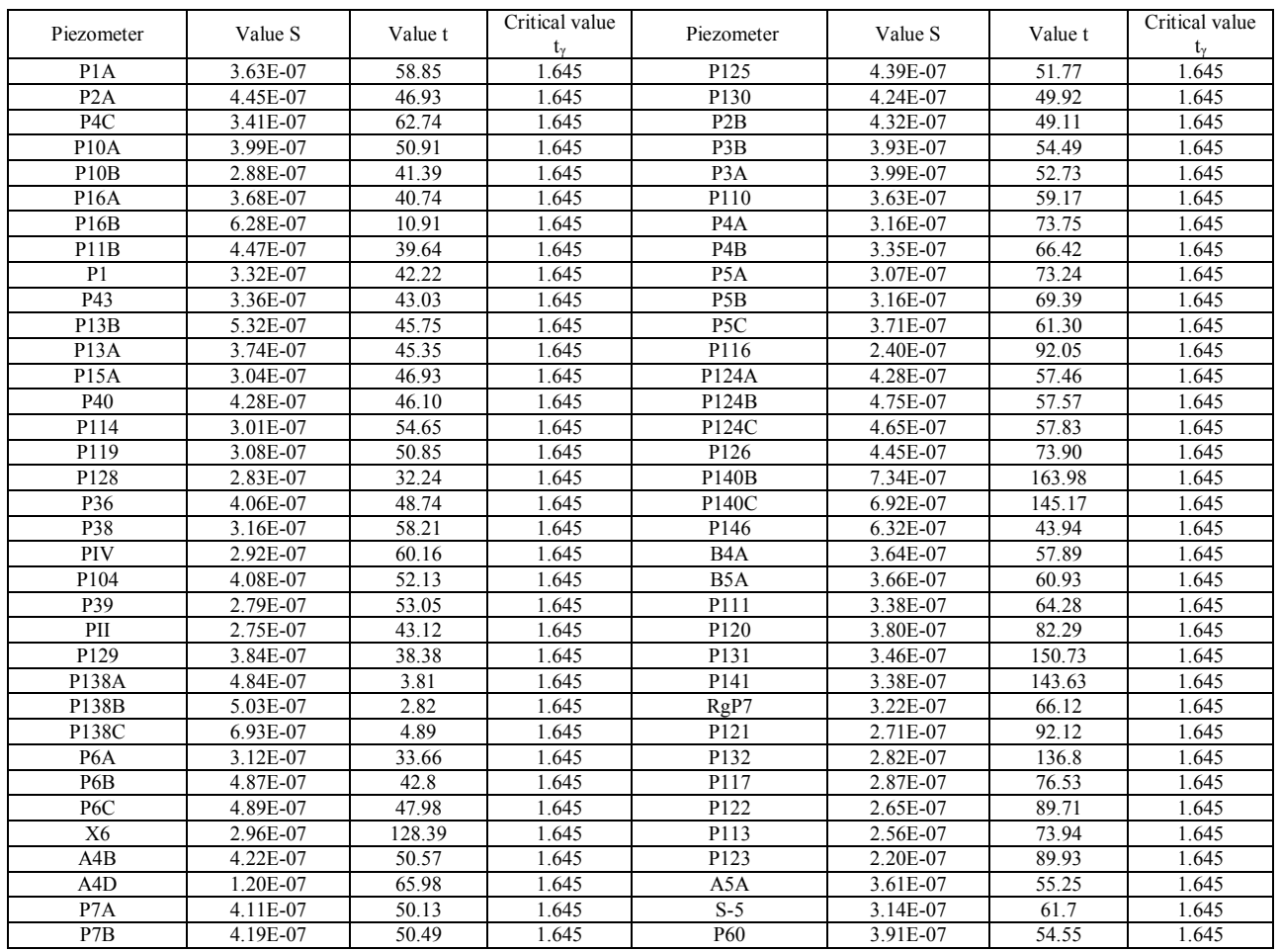




\begin{tabular}{|c|c|c|c|c|c|c|c|}
\hline P8A & $3.50 \mathrm{E}-07$ & 59.81 & 1.645 & P61 & $3.04 \mathrm{E}-07$ & 68.56 & 1.645 \\
\hline P8B & $3.53 \mathrm{E}-07$ & 59.36 & 1.645 & P62 & $3.04 \mathrm{E}-07$ & 70.49 & 1.645 \\
\hline P8C & $3.52 \mathrm{E}-07$ & 60.81 & 1.645 & P63 & $3.39 \mathrm{E}-07$ & 59.82 & 1.645 \\
\hline P9A & $3.91 \mathrm{E}-07$ & 53.90 & 1.645 & P64 & $3.7 \mathrm{E}-07$ & 32.21 & 1.645 \\
\hline P9B & $3.35 \mathrm{E}-07$ & 63.41 & 1.645 & P145 & $3.92 \mathrm{E}-07$ & 38.17 & 1.645 \\
\hline P9C & $3.39 \mathrm{E}-07$ & 65.16 & 1.645 & P150 & $2.91 \mathrm{E}-07$ & 73.38 & 1.645 \\
\hline
\end{tabular}

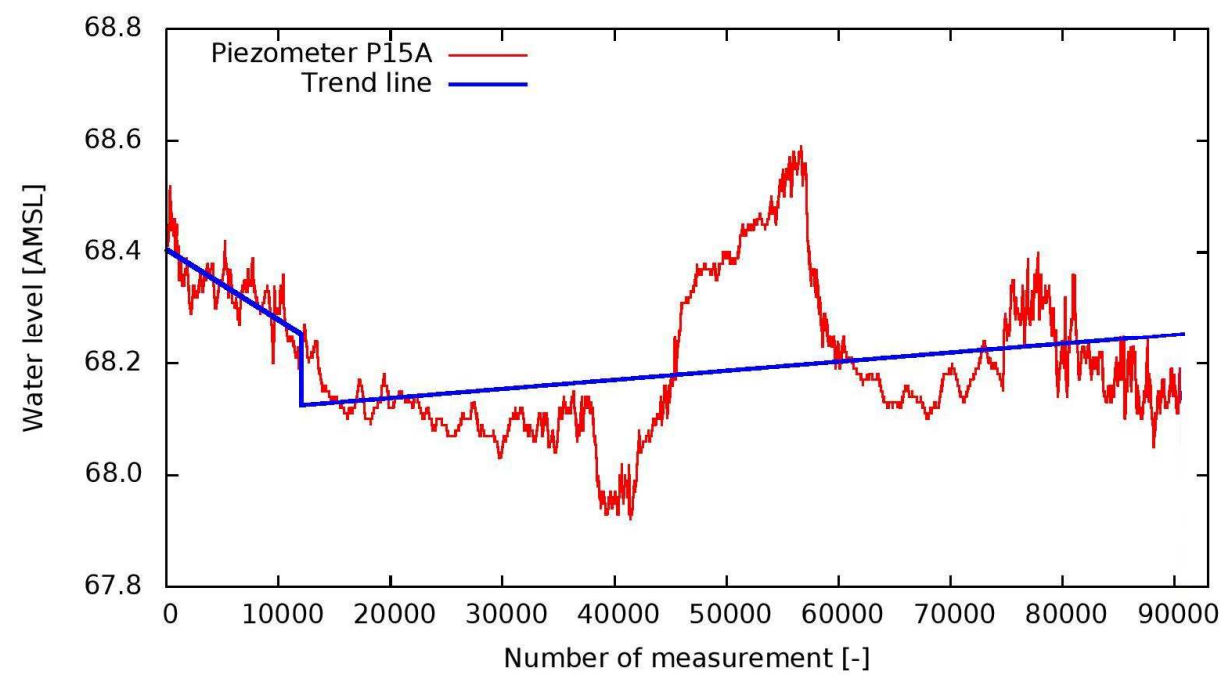

Fig. 3. Time series of water level changes in the P15A piezometer with a trend line for the dam in Pieczyska from January 2016 to April 2017.

\section{Discussion and conclusions}

Out of the 82 analyzed open standpipe piezometers of the dam in Pieczyska, in zero cases there are no grounds to reject the hypothesis of equality of linear regression coefficients, taking into account the period from January 2016 to February 2016 and from March 2016 to April 2017. This means that for $100 \%$ piezometers, the trend of water levels changed. In most cases $(87.8 \%)$, this was an increasing trend, which would lead to an increase in the values of seepage gradients. In ten of the studied piezometers (P114, PII, P129, P138A, P138B, P138C, P9C, P125, P5C, P124B), in the period from March 2016 to April 2017, the trend was decreasing. The reasons for the observed change in the trend of water levels and the increase in the seepage pressure in these piezometers require further clarification. Further observation of water levels and possible model tests are necessary to explain this phenomenon.

The dam in Pieczyska, which does not have any impervious elements, allows seepage through its structure. Therefore, the water from the reservoir constantly seeps to the lower reservoir. The water flowing through the core and foundation exerts pressure on the soil. The pressure, in relation to the volume unit of the ground, is nothing but the flow-off pressure which is directed according to the direction of seepage (tangentially to the line of the current). The flow-off pressure does not depend on the seepage speed, but only on the hydraulic slope, it overcomes the frictional force of water against grains and soil particles and causes the movement of fine soil particles towards the lower reservoir. The accumulation of small particles of soil results in the sealing of the given region, and as a consequence, water accumulation due to disruption of the privileged path of its flow, which eventually causes an increase in the pressure. When the pressure exceeds the critical value, there is a seepage failure associated with the outflow of water and the upheaval of the soil material. This phenomenon will occur systematically until all fine soil fractions are rinsed 
from the dam and its substrate. An additional element causing a local increase in seepage pressure is the colmatation of drainage holes. It would therefore be necessary to replace the reverse filters located at the ends of the outflow channels, and to replace the concrete bottom and side plates of the lower reservoir with an openwork structure (gabions) arranged on the reverse filter, so as to allow the outflow of water.

The paper has been prepared within the scope of the AGH UST statutory research no. 11.11.150.008.

\section{References}

1. S. Lach, L. Opyrchał. Jou. Wat. La. Dev. 33, 89 (2017)

2. Z. Kledyński. Mod. Build. Eng. 2, 54 (2011)

3. S. Lach. Jou. Eco. Eng. 19, 150 (2018)

4. S. Lach. Using the modified scalar product approach for testing the direction of seepage through the earth-fill dams (AGH University of Science and Technology Press, Krakow, 2016)

5. R.Fell R, M. Foster, M. Spannagle. Can. Geot. Jou. 37, 1000 (2000)

6. K. Fiedler, J. Gamdzyk, W. Jankowski, L. Opyrchał, S. Selerski, A. Wita., M. Wróblewski. Dam accidents and disaster - hazards, their causes and effects and preventive actions. (Monographs of the Institute of Meteorology and Water Management, Warsaw, 2007)

7. Materials of the Koronowo Hydroelectric Power Station

8. S. Lach, L. Opyrchał. Wat. Engin. 77, 407 (2017)

9. R.D. Gibbons. Statistical methods for groundwater monitoring (John Wiley \& Sons, New York, 1994) 